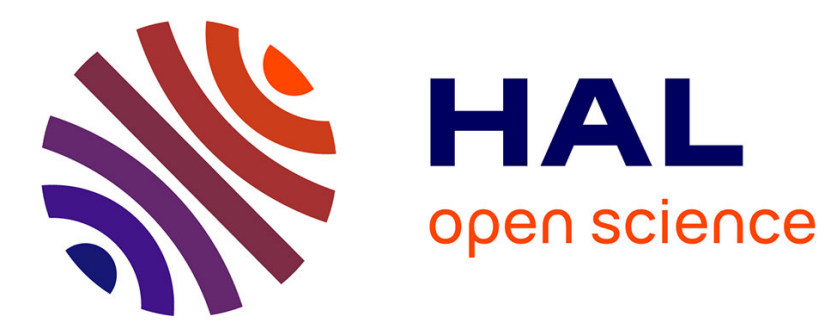

\title{
Prediction of deformations during endovascular aortic aneurysm repair using finite element simulation.
}

\author{
Adrien Kaladji, Aurélien Dumenil, Miguel Castro, Alain Cardon, Jean-Pierre
}

Becquemin, Benyebka Bou-Saïd, Antoine Lucas, Pascal Haigron

\section{To cite this version:}

Adrien Kaladji, Aurélien Dumenil, Miguel Castro, Alain Cardon, Jean-Pierre Becquemin, et al.. Prediction of deformations during endovascular aortic aneurysm repair using finite element simulation.. Computerized Medical Imaging and Graphics, 2013, 37 (2), pp.142-9. 10.1016/j.compmedimag.2013.03.002 . hal-00879891

\section{HAL Id: hal-00879891 \\ https://hal.science/hal-00879891}

Submitted on 7 Nov 2013

HAL is a multi-disciplinary open access archive for the deposit and dissemination of scientific research documents, whether they are published or not. The documents may come from teaching and research institutions in France or abroad, or from public or private research centers.
L'archive ouverte pluridisciplinaire HAL, est destinée au dépôt et à la diffusion de documents scientifiques de niveau recherche, publiés ou non, émanant des établissements d'enseignement et de recherche français ou étrangers, des laboratoires publics ou privés. 


\section{PREDICTION OF DEFORMATIONS DURING \\ ENDOVASCULAR AORTIC ANEURYSM REPAIR USING FINITE ELEMENT SIMULATION}

Adrien Kaladji ${ }^{1,2,3}$, Aurélien Dumeni1 ${ }^{2,3}$, Miguel Castro ${ }^{2,3}$, Alain Cardon ${ }^{1}$, Jean-Pierre Becquemin $^{4}$, Benyebka Bou-Saïd ${ }^{5}$, Antoine Lucas ${ }^{1,2,3}$, Pascal Haigron ${ }^{2,3}$

(1) CHU Rennes, Department of cardiothoracic and vascular surgery, F-35033 Rennes, France

(2) INSERM, U1099, F-35000 Rennes, France

(3) University Rennes 1, Signal and Image Processing Laboratory (LTSI), F-35000 Rennes, France

(4) Henri Mondor Hospital, Department of Vascular and Endovascular surgery, University of Paris

(5) Université de Lyon, CNRS INSA-Lyon, LaMCoS, UMR5259, F-69621, France

\section{Corresponding author:}

Adrien Kaladji, Service de Chirurgie Cardiovasculaire et thoracique, CHU Hôpital Pontchaillou, 2 rue Henri Le Guilloux, Bloc central, $7^{\text {ème }}$ étage, Service Leriche, 35033 Rennes cedex 9, France

Phone number : +33299289569

Email: kaladrien@hotmail.fr 


\begin{abstract}
During endovascular aortic aneurysm repair (EVAR), the introduction of medical devices deforms the arteries. The aim of the present study was to assess the feasibility of finite element simulation to predict arterial deformations during EVAR. The aortoiliac structure was extracted from the preoperative CT angiography of fourteen patients who underwent EVAR. The simulation consists of modeling the deformation induced by the stiff guidewire used during EVAR. The results of the simulation were projected onto the intraoperative images, using a 3D/2D registration. The mean distance between the real and simulated guidewire was $2.3 \pm 1.1 \mathrm{~mm}$. Our results demonstrate that finite element simulation is feasible and appears to be reproducible in modeling device/tissue interactions and quantifying anatomic deformations during EVAR.
\end{abstract}




\section{Introduction}

The deployment of an aortic stent graft requires the introduction of rigid sheaths and guidewires via a femoral access, which then leads to deformations of the vascular structures, which by nature are soft. This is the main source of rigid registration errors when the preoperative 3-dimensional (3D) computed tomography angiography (CTA) is overlayed onto the 2-dimensional (2D) fluoroscopy images taken during endovascular abdominal aortic aneurysm (AAA) repair. When these intraoperative arterial deformations occur, they also lead to length changes, of the iliac arteries in particular. These arteries are measured at the time of sizing, in order to determine, from a limited catalogue, which stent graft is the most suitable for the patient. This process leads to an obvious paradox: the deformations are not objectively taken into account at the time of sizing/planning and of guiding of the procedure, whereas the stent graft is deployed inside a deformed artery, which will not have the same length as that measured on the CTA. Currently, the physician anticipates such deformations, on the basis of his experience, but not on physical or statistical deformation data.

A few works have focused on computer aided navigation to assist endovascular repair of complex aortic aneurysms. Indeed, most of vascular surgeons work with a standard intraoperative 2D fluoroscopy-like imaging. For endovascular aortic aneurysm repair (EVAR), the best imaging to guide the intervention is the superimposition of the pre-operative $\mathrm{CT}$ volume onto the intra-operative imaging environment thanks to a registration process ${ }^{1}$. Intensity based $^{2,3}$ and feature based ${ }^{4,5} 3 \mathrm{D} / 2 \mathrm{D}$ rigid registration methods have been considered. Due to intra-operative deformations of vascular structures it is difficult to achieve an accuracy of about one millimeter. More recent works integrated non-rigid registration to take into consideration local deformations, of the renal ostia, observed between 3D CT pre-operative data and intra-operative images. The results reported from use of the image-guided surgery system during 23 procedures showed that the method was within a target accuracy of $3 \mathrm{~mm}$ in $78 \%$ of cases. The deformation of the iliac arteries caused by the introduction of stiff endovascular tools was not taken into account. Otherwise several works attempted to implement Finite Element Methods (FEM) based simulation in the context of endovascular procedures. They were intended to deal with issues related to the understanding and the anticipation of aneurysm rupture risk, of strain, migration and endoleaks at the stent, in their pre-computed implementation ${ }^{6-8}$ or to deal with catheterization simulation issues in their interactive / real time implementation ${ }^{9,10}$. With the extension of EVAR to more complex cases, in particular to the use of a fenestrated endograft in certain patients, the quantification 
of vascular deformations will become an important aspect in the planning and sizing of such devices. In addition, such deformations will need to be accounted for by the intraoperative imaging fusion system. The aim of this study was to assess the feasibility of finite element simulation to predict and quantify arterial deformations during EVAR

\section{Material and methods}

\section{Patient and device data}

From January 2011 to March 2011, CTA data was obtained from 14 consecutive patients (13 men) with an AAA who underwent EVAR in our department. The patients were operated when the aneurysm diameter exceeded the threshold of $50 \mathrm{~mm}$. Their mean age was $73.5 \pm 8.9$ years. This study was approved by our hospital's ethics committee. The CTAs were performed using a 64-slice scanner (General Electric Medical Systems, Milwaukee, Wisconsin, LightSpeed16). The data acquisition parameters were: slice thickness $=1.25 \mathrm{~mm}$, using a 215-260 mA, $120 \mathrm{kVp}$ tube. $120 \mathrm{ml}$ of a non-ionised iodine contrast medium (Hexabrix, Guerbet LLC, Bloomington, Ind) were injected via an antecubital vein with a 3.5 $\mathrm{mL} / \mathrm{s}$ flow rate (iodine concentration of $320 \mathrm{mg} / \mathrm{ml}$ ). The grayscale windowing of the tissue was 400 Houndsfield units (HU) at the periphery and $40 \mathrm{HU}$ at the center. The one month postoperative CTAs were carried out according to this protocol, in addition to a delayed acquisition in order to detect any possible low flow-rate endoleak and so 2 CTAs were available for each patient.

The CTAs were analyzed using the Endosize ${ }^{\circledR}$ software ${ }^{11}$ (Therenva, Rennes, France). The image analysis process combines contour-based and region-based segmention algorithms including morphological operations to automatically remove connections between the vasculature of interest (aortoiliac structure) and bone structures (such as spine). The vessel centerlines and contours, as well as the surface description of the vascular lumen were extracted from the CTAs. The aorto-spinal distance was also considered. It was obtained by computing beforehand a Maurer distance map ${ }^{12}$ from the bone structures. The vascular structures were described using active contours, and were represented by curves (B-spline type) in planes orthogonal to the centerline of each vessel. For each patient, 1 spline per $\mathrm{cm}$ (with 8 points/spline) was extracted, from the abdominal aorta to the femoral arteries. The 3D coordinates of three points defining each of the planes (one point along the centerline and two additional coplanar points) as well as the in-plane coordinates of the vessel lumen contour points were exported to the simulation software. For each patient, a complete sizing was 
performed according to the standards of the international society for vascular surgery ${ }^{13}$. P2 corresponded to the measurement point on the centerline immediately below the renal arteries, P3 to the end of the aortic neck, P4 to the aortic bifurcation, P5 and P6 to the left and right iliac bifurcations respectively (Fig. 1). P1, P7 and P8 corresponded to the extremities of the region of interest and were not considered as measurement points. On the post-operative CTA at 1 month, only the lengths were analyzed. They were measured using the same reference points $(\mathrm{P} 2, \mathrm{P} 3, \mathrm{P} 4, \ldots)$ as on the preoperative CTA. In addition to these quantitative variables, the arterial wall quality (healthy wall, calcifications) was determined according to the grading system based on the recommendations of the international society for vascular surgery ${ }^{13}$. The grade 0 corresponded to a healthy wall and the (maximum) grade 3 corresponded to circular calcifications of the whole artery.

\section{Simulation}

Reconstruction of the vascular geometry was achieved using the ANSYS DesignModeler software (ANSYS, Inc., Canonsburg, PA). The contours were imported from Endosize ${ }^{\circledR}$, and by using a surface interpolation tool, the full aortic surface was recreated (Fig. 2). From this geometric model (Fig. 2), a triangular mesh was generated and contained (depending on the patient) between 5000 and 10000 shell elements ${ }^{14}$. The thickness of the artery wall was $1.5 \mathrm{~mm}$ on the aorta and $1 \mathrm{~mm}$ on the iliac arteries. The vascular wall was considered to be homogeneous, isotropic and incompressible, with a Poisson's ratio of 0.45 . A linear elastic model was used to describe the deformation properties of the arterial wall. The mechanical properties of the artery wall were determined from the calcification grade, determined from the sizing. Based on the literature ${ }^{15-18}$ the values of Young's Modulus (defining the elasticity) were applied as follows: non or minimally calcified artery (grade 0 or 1): $2 \mathrm{MPa}$; calcified artery (grade 2): $5 \mathrm{MPa}$; highly calcified artery (grade 3): $10 \mathrm{MPa}$

The guidewire used for the simulations was the Lunderquist ${ }^{\circledR}$ (Extra Stiff Wire Guide, Cook $\left.{ }^{\circledR}\right)$ model. Its mechanical characteristics were studied using an LF-Plus ${ }^{\circledR}$ device (Lloyd instruments), which allows tension and bending tests to be carried out using extensometer and crosshead technologies. It was modeled as a cylinder with a hemisphere at its end. The characterization of the mechanical properties of the guidewire allowed varying material properties to be defined, depending on whether the flexible distal end $(4 \mathrm{~cm})$ or the more rigid body of the guidewire was considered. A progressive stiffness gradient was applied to the transition zone between the flexible and rigid sections of the guidewire ${ }^{20}$. The guidewire mesh 
was comprised of approximately 1000 hexahedral elements. The parameters used for the rigid section were: $180 \mathrm{GPa}$ for Young's modulus, and 0.3 for the Poisson's ratio.

The boundary conditions are the parameters defining the mechanical stresses or displacements acting on the geometric structure under consideration from external sources. They can take different forms as fixed points (fixed support) or spring stiffness per unit area that only acts in the direction normal to the face of the mesh (elastic support). Specific anatomical features were considered, when selecting suitable positions for the fixed supports. The upper extremity of the abdominal aorta (coeliac aorta) is fixed by the aortic hiatus which is an opening in the diaphragm. The aortic hiatus is an extension of the diaphragmatic pillars which are strong tendinous layers very close to the spine. The femoral artery is also laterally held in the femoral triangle by its collaterals laterally and the inguinal ligament forwards. Between the coeliac aorta and the femoral artery, there is no other strong anatomical structure to which the aortoiliac structure can be attached. Thus in the present study, the boundary edges of the mesh corresponding to the coeliac part of the abdominal aorta and the guidewire insertion site on the femoral artery were assumed to be fixed. Elastic supports were used to model the anatomical relationship between the posterior side of the aorta and the anterior side of the spine. The stiffness was chosen to be proportional to the distance between the aorta and the spine ${ }^{20}$, computed beforehand from a distance map. Other supports were added between the aortic bifurcation and the internal iliac bifurcation.

The simulations were made on a Hewlett Packard Z800 computer (HP Development Company, California, USA), with an 8-core, $2.4 \mathrm{GHz}$ Xeon processor. The method used involved displacing the guidewire onto the centerline of the aortoiliac structure, using prestress to initialize the guidewire/artery interactions (Fig. 3). The pre-stress was then removed and the guidewire/artery contact activated.

\section{Pre-/intra-operative registration}

In order to evaluate the results of our simulation, the simulated guidewire was projected onto the intraoperative image of the operated patient, and then compared with the real guidewire. 2D/3D registration was implemented in order to align the preoperative 3D simulation with the $2 \mathrm{D}$ intraoperative images. The $2 \mathrm{D}$ intraoperative centerlines were extracted from a frontal digital substraction angiography (DSA) performed at the beginning of the procedure. The image included the entire abdominal aorta and the femoral arteries. When this DSA were recorded, no device able to deform the aortoiliac structure was present within the arteries. Following DSA acquisition of the DSA, the lunderquist was inserted until its final 
position with no displacement of the c-arm. This protocol allowed the registration between the preoperative 3D centerlines extracted from the CTA and the 2D intraoperative centerlines extracted from the undeformed DSA. The geometrical transformation between the preoperative $3 \mathrm{D}$ coordinate system (CTA) and the intraoperative $2 \mathrm{D}$ coordinate system (fluoroscopy) was estimated using a feature-based similarity measurement, based on the distances between the centerlines of the vascular structures computed in the intraoperative image $^{1,21}$. It was then possible to use this transformation to make a projection of the simulated guidewire superimposing it onto the 2D fluoroscopy image of the real guidewire. Thus for each patient, the simulation was assessed on the basis of two errors (Fig. 4). The first of these was the error associated with the registration procedure, which was calculated from the mean distance (Euclidean 2D distance) between the centerlines on the preoperative 3D image and those on the $2 \mathrm{D}$ intraoperative image. The second error was that associated with the simulation, which was computed by measuring the mean distance between the simulated and real guidewires. These distances were obtained from a distance map.

For the first 10 patients in this series (group A), the simulations were adjusted according to the outcomes they produced, thus allowing the model parameters to be tuned. In this training group, the location and the value of the elastic supports were adjusted interactively to minimize the simulation error. For the last 4 patients (group B), this model was applied with no retroactive corrections.

\section{Quantification of the deformations}

Using the simulation specific to each patient, which was initially parameterized and validated by comparison with the intraoperative data, the guidewire deformations were quantified by displacing equidistant points $(20 \mathrm{~mm})$ of the undeformed structure's centerline onto the deformed structure, as shown in Fig. 5. For each patient, the length of the displacement vector, between equivalent points on the deformed and undeformed centerline, in addition to its $(\mathrm{x}, \mathrm{y}, \mathrm{z})$ coordinates and the computing time needed for the simulation, were recorded. For each segment of the aorta and the iliac arteries, the preoperative, intraoperative, and post-operative lengths were measured.

The data are represented by: the mean \pm standard deviation for quantitative variables; their number and percentage for qualitative variables. Registration and simulation errors were compared between groups using the Mann-Whitney test. Correlations between variables were determined using Spearman's rank correlation coefficient. For the full set of analyses, a value of $\mathrm{P}<0.05$ was considered to be significant. 


\section{Results}

The mean values of the variables relevant to sizing are presented in Table 1 . The value of the maximum aneurysm diameter was 54.8 (first quartile $51.3 \mathrm{~mm}$, third quartile $56.8 \mathrm{~mm}$ ).

\section{Registration and simulation errors}

The average value of the registration error was $1.5 \pm 0.4 \mathrm{~mm}$, a maximum value of $2.2 \mathrm{~mm}$ was found in patient 5 , and a minimum value of $0.9 \mathrm{~mm}$ in patient 8 . The registration error (Table 3 ) was significantly correlated with the aortic neck angulation $(\mathrm{P}=0.016)$ and the AAA tortuosity index $(\mathrm{P}=0.014)$. There was no difference between the registration error in groups $\mathrm{A}$ and $\mathrm{B}(1.6 \pm 0.4 \mathrm{~mm}$ and $1.3 \pm 0.3 \mathrm{~mm}$ respectively, $\mathrm{P}=0.20)$ (Table 4).

The mean error associated with the simulation (including the registration error) was $2.3 \pm 1.1 \mathrm{~mm}$ for the full set of patients, with a maximum of $4.8 \mathrm{~mm}$ for patient 11 and a minimum of $0.9 \mathrm{~mm}$ for patient 1 (Table 2). This error was significantly correlated with the maximum angle of the iliac axis $(\mathrm{P}=0.046)$ and the tortuosity index of the aortic neck $(\mathrm{P}=0.047$ ) (Table 3). The mean computing time for the simulation (Table 2) was $20.7 \pm 8.2$ minute (minimum 12.4; maximum 38.2 minutes). For example, time for the entire process was 15 minutes for data extraction, 18 minutes for simulation and 2 minutes for registration (patient 10). There was no difference between the simulation errors in groups A and B $(2.1 \pm 0.9$ and $2.8 \pm 1.7$ respectively, $\mathrm{P}=0.83)$ (Table 4). Based on the superimposition of the deformed volume onto the intraoperative imaging (Fig.6), a qualitative assessment of the results of the simulation showed that the real guidewire was plausibly placed into the deformed artery compared to the preoperative (non deformed) volume for each patient.

\section{Values of the elastic supports}

The simulation error in group A was optimized by adjusting the values of elastic supports, as described in the following. A value of $5.10^{-3} \mathrm{~N} / \mathrm{mm}^{3}$ was determined for the elastic support between the aorta and the spine. This value was then readjusted taking the distance between the aorta and the spine into account. The elastic support was weighted by a coefficient, determined as a function of the distance between the aorta and the spine, equal to 1 when the distance was touching the spine and 0 when their separation was equal to the aortic neck diameter. Between 0 and 1, the relationship was assumed to be linear. The values of the elastic supports between the aortic bifurcation and the iliac bifurcation were adjusted as a function of the calcification grade, and were as follows: $1.10^{-3} \mathrm{~N} / \mathrm{mm}^{3}$ for grade 0 or $1,25.10^{-3}$ $\mathrm{N} / \mathrm{mm}^{3}$ for grade 2 , and $5.10^{-3} \mathrm{~N} / \mathrm{mm}^{3}$ for grade 3 . 


\section{Quantification of deformations}

The mean displacement was $0.7 \pm 0.3 \mathrm{~mm}$ at point $\mathrm{P} 2,1.4 \pm 0.8 \mathrm{~mm}$ at point $\mathrm{P} 3$, $1.4 \pm 1.1 \mathrm{~mm}$ at point P4, and $10.2 \pm 3.3 \mathrm{~mm}$ at point P5 (or P6). Figs. 7-10 provide the total displacement length (norm of the displacement vector of a point, from the undeformed mesh to the deformed mesh), and along the $\mathrm{x}, \mathrm{y}$ and $\mathrm{z}$ axes. This length is given for all points on the mesh, from the upper extremity of the studied volume (i.e. the coeliac aorta, used as the origin of the graphical reference system) to the lower extremity (i.e. the common femoral arteries). Fig. 7 shows that the greatest displacement occurred at the level of the external iliac arteries, followed by the common iliac arteries. At the level of the aortic neck (P2-P3) and the aneurysm (P3-P4), the displacement was small in all directions ( $\mathrm{x}, \mathrm{y}$ or $\mathrm{z}$ in Figs. 8, 9 and 10). Fig. 8 shows that displacements along the $\mathrm{x}$ axis were mainly "positive" at the iliac arteries, corresponding to a displacement towards the anatomic midline of the aortoiliac structure. Fig. 9 shows that the displacement of the iliac arteries was mainly "negative", corresponding to a rearward movement. Fig. 10 shows that the displacements of the iliac arteries varied along their length. At the level of the common iliac arteries, the displacement was "positive", i.e. upwards. At the level of the external iliac arteries, the displacement was "negative", i.e. downwards.

\section{Discussion}

In this study we present for the first time a technique for the quantification of anatomic deformations during EVAR procedures, thanks to the use of "patient-specific" numerical simulations. Other applications of finite element simulations have been proposed, for the placement of a stent in the context of EVAR procedures ${ }^{22}$, or in the peripheral vessels ${ }^{23-27}$. The main purpose of these prior applications was to study mechanical stresses between the stent and vessel wall during the placement of the former in pathological vessels. The geometry of the arteries, as well as the values of the material properties were not based on patient-specific data, but on standard values found in the literature. In our study, each simulation took the patient's geometry into account, and the material property values (Young's modulus) were adapted according to the arterial wall quality of the patient's arteries.

In order to propose a preliminary model, various simplifying hypotheses were made. Our approach involved finding a suitable compromise between a very accurate simulation and 
a less accurate simulation suitable for use in a clinical environment. The aim of the present study was thus to assess the clinical feasibility and usefulness of the proposed technique. Although the model proposed here could clearly be upgraded in future developments, our initial research shows that this technique can be used in clinical applications and is compatible with the current practice.

Indeed, one of the limitations of the present study is the absence of the aneurysmal thrombus and the surrounding tissues in the description of the aortic wall and the boundary conditions. The presence of the thrombus could influence the aortic wall thickness, especially in the vicinity of the aneurysmal sac. Even if the thrombus were not considered, its biomechanical properties could be applied to the mesh. Moreover, the thrombus is located in the aneurysmal sac where the lumen is very wide. Very frequently, the guidewire is not in contact with the aortic wall in this aortic segment. Finally, although neither the thrombus nor variations in aortic wall thickness were taken into account, the results of the simulation appear to be acceptable, with respect to the given clinical issue.

Several simulation trials, not described in detail in this study, were made in order to find the most robust method. One of the methods involved running a simulation, which reproduced the chronology of the intervention, i.e. the progressive insertion of the guidewire from the femoral access to the thoracic aorta. This method would have considered the frictional forces due to the device insertion. But this method was not robust and had a high computing cost as a consequence of the large number of equations to be solved (in terms of guidewire-wall contacts), at each "step" of the guidewire's insertion. In view of these limitations, a pragmatic approach was adopted, focusing on the main clinical issue addressed in this paper, i.e. the prediction of intraoperative tissue deformations when the guidewire is fully inserted prior to deployment of the stentgraft.

In our study, the biomechanical properties of the vessels obeyed a linear elastic model ${ }^{28,}$ 29 , whereas a hyperelastic model ${ }^{30}$ has often been reported by other authors ${ }^{31-35}$ for the modeling of vascular tissue behavior. Nevertheless, Scherer et $\mathrm{al}^{8}$. have shown that a linear elastic model could also be used in simulations describing arterial behavior during stent placement. More importantly than the biomechanical laws of materials, the boundary conditions have a non-negligible influence on the outcome of the simulation. The use of elastic supports, in an attempt to model the stresses induced by anatomical interactions between arteries, was not based on known or previously studied data. By consulting the expert knowledge of surgeons, it was possible to localize these constraints. Since no data could be 
found in the literature on this topic, it was necessary to adjust the initially used stress values to the first set of data derived from the patients in group A. The four following patients (group B) allowed us to test the predictive nature of the model. This appears to have been well adjusted, since there was no difference between the two groups in terms of registration and simulation errors. These results must of course be confirmed with a larger number of patients. Our results show that even though it was small, the registration error was correlated with aortic neck angulation. Carrel et $\mathrm{al}^{2}$. have emphasized the limitations of rigid registration in the case of tortuous necks. Beyond an angulation of $30^{\circ}$, the deformation imposed by guidewires and delivery systems was too significant, and this study showed a significant difference between the preoperative projected $3 \mathrm{D}$ volume and the fluoroscopic image. However, the deformation graphs show that most preoperative deformations are located at the iliac arteries, the external iliac arteries in particular. In addition, the displacements of the aortic and iliac bifurcations are very small. This means that these zones should be considered to be nearly fixed, and that between them, arterial shortening occurs in the case of tortuous arteries during the insertion of a rigid device. This deformation could almost be compared with the movements of an accordion ${ }^{36}$.

In the case of the technique described here, only the displacement of the centerline was assessed. The displacement of each individual point on the mesh was not analyzed, and for this reason it would have been very difficult to draw any conclusions on possible displacements of the renal and visceral ostia arteries. In current practice, the superior and inferior movements of the renal arteries, in particular for the case of a coronal view, are determinant when it comes to avoiding renal coverage during deployment. If more detailed knowledge of this movement is required, the simulation will also need to model the stentgraft sheath. Such a full simulation would also involve longer computing times.

As mentioned in the introduction, sizing is currently carried out using an undeformed anatomy. Although the present study describes a technique which can be used to quantify deformation during EVAR, it is difficult to conclude that sizing should be performed on a deformed anatomy. It is not known whether the aortoiliac structure returns to its anatomical shape after deployment, especially in the case of challenging anatomies (calcified and tortuous cases), for which simulations could be of considerable added value. There is currently no information in the literature concerning the deformations induced by the stentgraft alone. Indeed, the vascular lumen and the position of the aortic bifurcation are considerably modified as a consequence of the shape of the stentgraft. One way to deal with this issue could be to objectively evaluate the deformations produced in the aortoiliac 
structure, during the pre-, per- and post-operative phases. The technique described in this study, based on patient-specific finite element simulations, is the first step towards achieving a better understanding of these issues.

Finally, another limitation of this study is its validation at only one angle of incidence. Indeed, the model is evaluated here only through the use of a 2D fluoroscopic image. Although the error arising from registration and simulation is small, it is important that these results be confirmed using a minimum of two incidence angles. This will be the subject of further studies.

\section{Conclusion}

Our results showed the feasibility and reliability of numerical simulation of device/tissue interactions during EVAR. This work could be used to preoperatively quantify and predict deformations. Beyond preoperative stent graft sizing, and combined to a $3 \mathrm{D} / 2 \mathrm{D}$ rigid registration process, it could be used to overlay pre-computed deformed 3D CTA data onto 2D fluroscopy images, thus providing an accurate augmented-reality tool to improve intra-operative stent-graft placement. This preliminary study needs to be confirmed with a larger population representing various anatomies, especially challenging ones.

\section{Acknowledgments}

The authors are indebted to the Centre of Clinical Investigation and Technological Innovation 804 for its support in the processing of imaging data. The work in this paper was partially funded by the French national research agency (ANR) through the Tecsan program (project ANGIOVISION nANR-09-TECS-003) and by the French Society for Vascular Surgery.

No competing interest declared 


\section{References}

1. Markelj P, Tomazevic D, Likar B, Pernus F. A review of 3D/2D registration methods for image-guided interventions. Medical image analysis. 2012;16(3):642-61. Epub $2010 / 05 / 11$.

2. Carrell TW, Modarai B, Brown JR, Penney GP. Feasibility and limitations of an automated 2D-3D rigid image registration system for complex endovascular aortic procedures. J Endovasc Ther. 2010 Aug;17(4):527-33.

3. G. Penney, A. Varnavas, N. Dastur, et T. Carrell. An image-guided surgery system to aid endovascular treatment of complex aortic aneurysms: description and initial clinical experience. Information Processing in Computer-Assisted Interventions, p. 13-24, 2011. 4. Goksu C, Haigron P, Acosta O, Lucas A. Endovascular navigation based on real/virtual environments cooperation for computer assisted TEAM procedures. Proceedings of SPIE Medical Imaging 2004:Visualization, Image-Guided Procedures, and Display; 2004; San Diego, USA: SPIE, Bellingham, WA; 2004. p. 257-66.

5. Goksu G, Haigron P, Zhang H, Soulas T, Le Certen G, Lucas A. 3D intraoperative localization for endovascular navigation guidance. Surgetica'2002, Computer-aided medical interventions: tools and applications; 2002; Grenoble, France ; Sauramps Medical; 2002. p. 323-9.

6. B. J. Doyle, A. Callanan, M. T. Walsh, P. A. Grace, T. M. McGloughlin, A finite element analysis rupture index (FEARI) as an additional tool for abdominal aortic aneurysm rupture prediction, Vasc Dis Prev, 2009, vol. 6, p. 114-121

7. Mortier P, Holzapfel GA, De Beule M, Van Loo D, Taeymans Y, Segers P, et al. A novel simulation strategy for stent insertion and deployment in curved coronary bifurcations: comparison of three drug-eluting stents. Annals of biomedical engineering. 2010;38(1):88-99. Epub 2009/11/10.

8. Molony DS, Kavanagh EG, Madhavan P, Walsh MT, McGloughlin TM. A computational study of the magnitude and direction of migration forces in patient-specific abdominal aortic aneurysm stent-grafts. European journal of vascular and endovascular surgery : the official journal of the European Society for Vascular Surgery. 2010;40(3):332-9. Epub 2010/06/25.

9. Lenoir J, Cotin S, Duriez C, Neumann P. Interactive physically-based simulation of catheter and guidewire, Computers \& Graphics, vol. 30, n. 3, p. 416-422, 2006. 
10. W. Tang, P. Lagadec, D. Gould, T.R. Wan, J. Zhai, et T. How a realistic elastic rod model for real-time simulation of minimally invasive vascular interventions, The Visual Computer, vol. 26, p. 1157-1165, 2010.

11. Kaladji A, Lucas A, Kervio G, Haigron P, Cardon A. Sizing for endovascular aneurysm repair: clinical evaluation of a new automated three-dimensional software. Ann Vasc Surg. 2010 Oct;24(7):912-20.

12. Maurer CR, Qi R, Raghavan V. Linear Time Algorithm for Computing Exact Euclidean Distance Transforms of Binary Images in Arbitrary Dimensions. IEEE Transactions on Pattern Analysis and Machine Intelligence. 2003 Feb ;25(2) : 265-270.

13. Chaikof EL, Fillinger MF, Matsumura JS, Rutherford RB, White GH, Blankensteijn JD, et al. Identifying and grading factors that modify the outcome of endovascular aortic aneurysm repair. J Vasc Surg. 2002 May;35(5):1061-6.

14. Richens D, Field M, Hashim S, Neale M, Oakley C. A finite element model of blunt traumatic aortic rupture. Eur J Cardiothorac Surg. 2004 Jun;25(6):1039-47.

15. Li Z, Kleinstreuer C. Blood flow and structure interactions in a stented abdominal aortic aneurysm model. Med Eng Phys. 2005 Jun;27(5):369-82.

16. Loree HM, Grodzinsky AJ, Park SY, Gibson LJ, Lee RT. Static circumferential tangential modulus of human atherosclerotic tissue. J Biomech. 1994 Feb;27(2):195-204.

17. Holzapfel GA, Sommer G, Regitnig P. Anisotropic mechanical properties of tissue components in human atherosclerotic plaques. J Biomech Eng. 2004 Oct;126(5):657-65.

18. Maier A, Gee MW, Reeps C, Eckstein HH, Wall WA. Impact of calcifications on patient-specific wall stress analysis of abdominal aortic aneurysms. Biomech Model Mechanobiol. 2010 Oct;9(5):511-21.

19. Schroder J. The mechanical properties of guidewires. Part I: Stiffness and torsional strength. Cardiovasc Intervent Radiol. 1993 Jan-Feb;16(1):43-6.

20. Penney GP, Weese J, Little JA, Desmedt P, Hill DL, Hawkes DJ. A comparison of similarity measures for use in 2-D-3-D medical image registration. IEEE Trans Med Imaging. 1998 Aug;17(4):586-95. 
21. Göksu C, Haigron P, Acosta O, Lucas A. Endovascular navigation based on real/virtual environments cooperation for computer assisted TEAM procedures. SPIE Medical Imaging : Visualization, Image-Guided Procedures, and Display; San Diego2004. p. 257-66.

22. Scherer S, Treichel T, Ritter N, Triebel G, Drossel WG, Burgert O. Surgical stent planning: simulation parameter study for models based on DICOM standards. Int J Comput Assist Radiol Surg. 2011 May;6(3):319-27.

23. Liang DK, Yang DZ, Qi M, Wang WQ. Finite element analysis of the implantation of a balloon-expandable stent in a stenosed artery. Int J Cardiol. 2005 Oct 10;104(3):314-8.

24. Migliavacca F, Petrini L, Colombo M, Auricchio F, Pietrabissa R. Mechanical behavior of coronary stents investigated through the finite element method. J Biomech. 2002 Jun;35(6):803-11.

25. Migliavacca F, Petrini L, Massarotti P, Schievano S, Auricchio F, Dubini G. Stainless and shape memory alloy coronary stents: a computational study on the interaction with the vascular wall. Biomech Model Mechanobiol. 2004 Jun;2(4):205-17.

26. Pericevic I, Lally C, Toner D, Kelly DJ. The influence of plaque composition on underlying arterial wall stress during stent expansion: the case for lesion-specific stents. Med Eng Phys. 2009 May;31(4):428-33.

27. Wu W, Wang WQ, Yang DZ, Qi M. Stent expansion in curved vessel and their interactions: a finite element analysis. J Biomech. 2007;40(11):2580-5.

28. Doyle BJ, Callanan A, McGloughlin TM. A comparison of modelling techniques for computing wall stress in abdominal aortic aneurysms. Biomed Eng Online. 2007;6:38.

29. Gao F, Watanabe M, Matsuzawa T. Stress analysis in a layered aortic arch model under pulsatile blood flow. Biomed Eng Online. 2006;5:25.

30. Raghavan ML, Vorp DA. Toward a biomechanical tool to evaluate rupture potential of abdominal aortic aneurysm: identification of a finite strain constitutive model and evaluation of its applicability. J Biomech. 2000 Apr;33(4):475-82.

31. Doyle BJ, Callanan A, Burke PE, Grace PA, Walsh MT, Vorp DA, et al. Vessel asymmetry as an additional diagnostic tool in the assessment of abdominal aortic aneurysms. J Vasc Surg. 2009 Feb;49(2):443-54. 
32. Fillinger MF, Marra SP, Raghavan ML, Kennedy FE. Prediction of rupture risk in abdominal aortic aneurysm during observation: wall stress versus diameter. J Vasc Surg. 2003 Apr;37(4):724-32.

33. Fillinger MF, Raghavan ML, Marra SP, Cronenwett JL, Kennedy FE. In vivo analysis of mechanical wall stress and abdominal aortic aneurysm rupture risk. J Vasc Surg. 2002 Sep;36(3):589-97.

34. Leung JH, Wright AR, Cheshire N, Crane J, Thom SA, Hughes AD, et al. Fluid structure interaction of patient specific abdominal aortic aneurysms: a comparison with solid stress models. Biomed Eng Online. 2006;5:33.

35. Wang DH, Makaroun MS, Webster MW, Vorp DA. Effect of intraluminal thrombus on wall stress in patient-specific models of abdominal aortic aneurysm. J Vasc Surg. 2002 Sep;36(3):598-604.

36. Quinn SF, Kim J, Sheley RC, Frankhouse JH. "Accordion" deformity of a tortuous external iliac artery after stent-graft placement. J Endovasc Ther. 2001;8(1):93-8. Epub 2001/02/28. 


\section{TABLES}

Table 1: Mean lengths (L1: preoperative, L2: intraoperative, L3: postoperative) of each segment of the aortoiliac structure. The tortuosity index $(\mathrm{T})$ and angles for each are measured on the preoperative CT

\begin{tabular}{lcccccc}
\hline & L1 & L2 & L3 & T & Ca & Angle \\
\hline Aortic neck & $33,8 \pm 16,9$ & $34,1 \pm 16,7$ & $32,2 \pm 16,4$ & $1,1 \pm 0,1$ & Grade 0 & $32,1 \pm 17,7$ \\
Aneurysm & $82,4 \pm 18,1$ & $82,1 \pm 17,9$ & $78,4 \pm 15,7$ & $1,1 \pm 0,05$ & Grade 1 & $148,2 \pm 15,5$ \\
Common iliac artery & $67 \pm 10,8$ & $59,5 \pm 10,8$ & $63,8 \pm 11,2$ & $1,1 \pm 0,1$ & Grade 1 & $146,9 \pm 13,8$ \\
External iliac artery & $130,9 \pm 28,2$ & $108,6 \pm 23$ & $130 \pm 23,2$ & $1,2 \pm 0,2$ & Grade 0 & $119,4 \pm 10,2$ \\
\hline
\end{tabular}

Table 2: Values of the registration and simulation error for each patient

\begin{tabular}{cccccc}
\hline Patient & $\begin{array}{c}\text { Registration } \\
\text { error }(\mathrm{mm})\end{array}$ & Range & $\begin{array}{c}\text { Distance between } \\
\text { stiff wires }(\mathrm{mm})\end{array}$ & Range & $\begin{array}{c}\text { Time } \\
(\mathrm{min})\end{array}$ \\
\hline 1 & $1,7 \pm 1,4$ & $0-5,4$ & $0,9 \pm 1,5$ & $0-2,7$ & 19,2 \\
2 & $1,8 \pm 1,4$ & $0-6,2$ & $2 \pm 1,1$ & $0-4,9$ & 15,6 \\
3 & $2 \pm 1,6$ & $0-6,5$ & $1,7 \pm 1,3$ & $0-4$ & 27,1 \\
4 & $2 \pm 1,8$ & $0-8,1$ & $2,1 \pm 1,2$ & $0-6,1$ & 16,6 \\
5 & $2,2 \pm 2$ & $0-7,8$ & $1,9 \pm 1,3$ & $0-4$ & 13,6 \\
6 & $2,1 \pm 1,5$ & $0-7,6$ & $4,1 \pm 1,3$ & $0-$ & 38,2 \\
7 & $1,1 \pm 1$ & $0-6$ & $2 \pm 0,9$ & $0-4,4$ & 13,2 \\
8 & $0,9 \pm 0,9$ & $0-5,9$ & $1,8 \pm 1,3$ & $0-5$ & 28,7 \\
9 & $1,4 \pm 1,1$ & $0-6,7$ & $3 \pm 1,7$ & $0-6,8$ & 12,7 \\
10 & $1,2 \pm 0,9$ & $0-4,3$ & $1,5 \pm 1,4$ & $0-6,8$ & 18,7 \\
11 & $1,2 \pm 0,9$ & $0-5,1$ & $4,8 \pm 2,6$ & $0-9$ & 12,4 \\
12 & $1,6 \pm 1,2$ & $0-7,6$ & $1,4 \pm 0,8$ & $0-4,8$ & 31 \\
13 & $1 \pm 0,8$ & $0-3,6$ & $1,5 \pm 1,2$ & $0-5,1$ & 27,1 \\
14 & $1,4 \pm 1$ & $0-7,8$ & $3,5 \pm 1,6$ & $0-6,2$ & 16,3 \\
\hline
\end{tabular}


Table 3: Correlation coefficient (r) between the sizing ant the results of the simulation (1: aortic neck, 2: aneurysm, 3:common iliac artery, 4 :external iliac artery)

\begin{tabular}{|c|c|c|c|c|}
\hline & $\begin{array}{l}\text { Registration } \\
\text { error }\end{array}$ & $\begin{array}{l}\text { Distance } \\
\text { between }\end{array}$ & $\begin{array}{l}\text { Maximum } \\
\text { aortic }\end{array}$ & $\begin{array}{c}\text { Maximum iliac } \\
\text { displacement }\end{array}$ \\
\hline \multirow[t]{2}{*}{ Angle 1} & $\mathrm{r}=0,66$ & $\mathrm{r}=0,28$ & $\mathrm{r}=0,33$ & $\mathrm{r}=0,16$ \\
\hline & $\mathrm{P}=0,016$ & NS & NS & NS \\
\hline \multirow{2}{*}{ Angle 2} & $\mathrm{r}=-0,49$ & $\mathrm{r}=0,05$ & $\mathrm{r}=-0,33$ & $\mathrm{r}=0,21$ \\
\hline & NS* & NS & NS & NS \\
\hline \multirow[t]{2}{*}{ Angle 3} & $\mathrm{r}=0,27$ & $\mathrm{r}=0,04$ & $\mathrm{r}=-0,12$ & $\mathrm{r}=0,33$ \\
\hline & NS & NS & NS & NS \\
\hline \multirow[t]{2}{*}{ Angle 4} & $\mathrm{r}=-0,36$ & $\mathrm{r}=-0,54$ & $\mathrm{r}=-0,43$ & $\mathrm{r}=-0,45$ \\
\hline & NS & $\mathrm{P}=0,046$ & NS & NS \\
\hline \multirow[t]{2}{*}{$\mathrm{T} 1$} & $\mathrm{r}=-0,03$ & $\mathrm{r}=0,54$ & $\mathrm{r}=0,32$ & $\mathrm{r}=0,14$ \\
\hline & NS & $\mathrm{P}=0,047$ & NS & NS \\
\hline \multirow[t]{2}{*}{$\mathrm{T} 2$} & $\mathrm{r}=0,6$ & $\mathrm{r}=-0,2$ & $\mathrm{r}=0,05$ & $\mathrm{r}=0,35$ \\
\hline & $\mathrm{p}=0,015$ & NS & NS & NS \\
\hline \multirow[t]{2}{*}{$\mathrm{T} 3$} & $\mathrm{r}=-0,04$ & $\mathrm{r}=0,35$ & $\mathrm{r}=-0,14$ & $\mathrm{r}=0,12$ \\
\hline & NS & NS & NS & NS \\
\hline \multirow[t]{2}{*}{$\mathrm{T} 4$} & $\mathrm{r}=0,04$ & $\mathrm{r}=-0,06$ & $\mathrm{r}=0,59$ & $\mathrm{r}=0,18$ \\
\hline & NS & NS & $\mathrm{P}=0,03$ & NS \\
\hline
\end{tabular}

Table 4: Registration and simulation error in group A and B

\begin{tabular}{lcccc}
\hline & Total $(\mathrm{n}=14)$ & Group A $(\mathrm{n}=10)$ & Group B(n=4) & p value \\
& & & & \\
\hline Registration error $(\mathrm{mm})$ & $1,5 \pm 0,4$ & $1,6 \pm 0,5$ & $1,3 \pm 0,3$ & 0,20 \\
Simulation error $(\mathrm{mm})$ & $2,3 \pm 1,1$ & $2,1 \pm 0,9$ & $2,8 \pm 1,6$ & 0,83 \\
\hline
\end{tabular}




\section{FIGURES}

Figure 1: Key points in the preoperative sizing

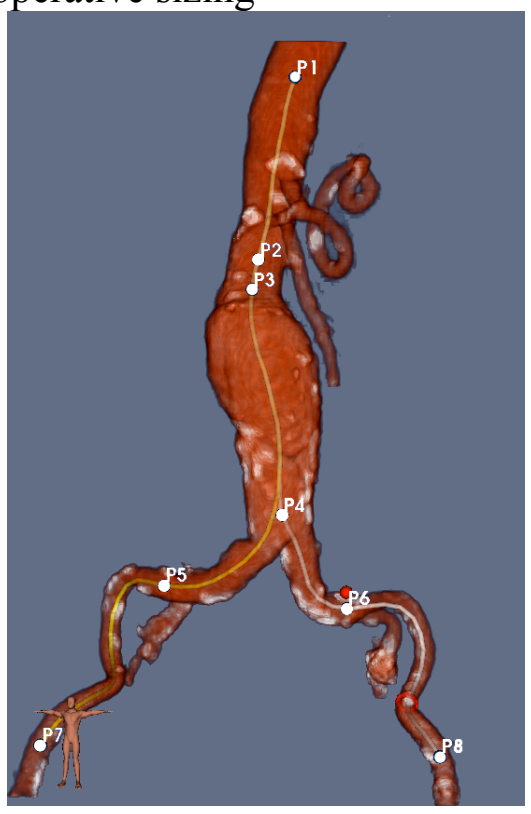

Figure 2: Aortoiliac surface reconstructed (on the left) and aortoiliac mesh generated (on the right)

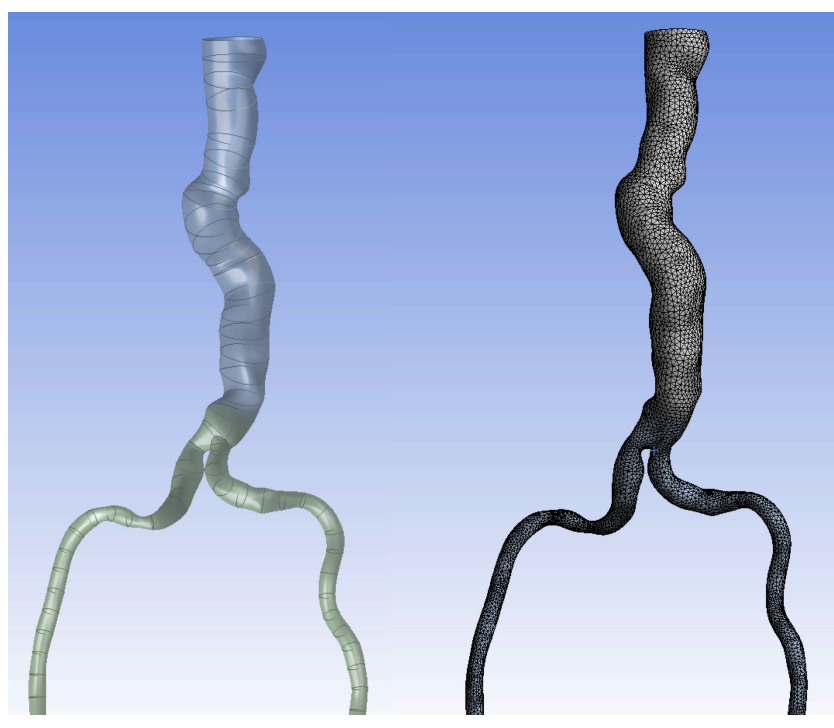


Figure 3: Steps of the simulation (left to right): The guidewire is strained on the vessel centerline and then relaxed to obtain an equilibrium state

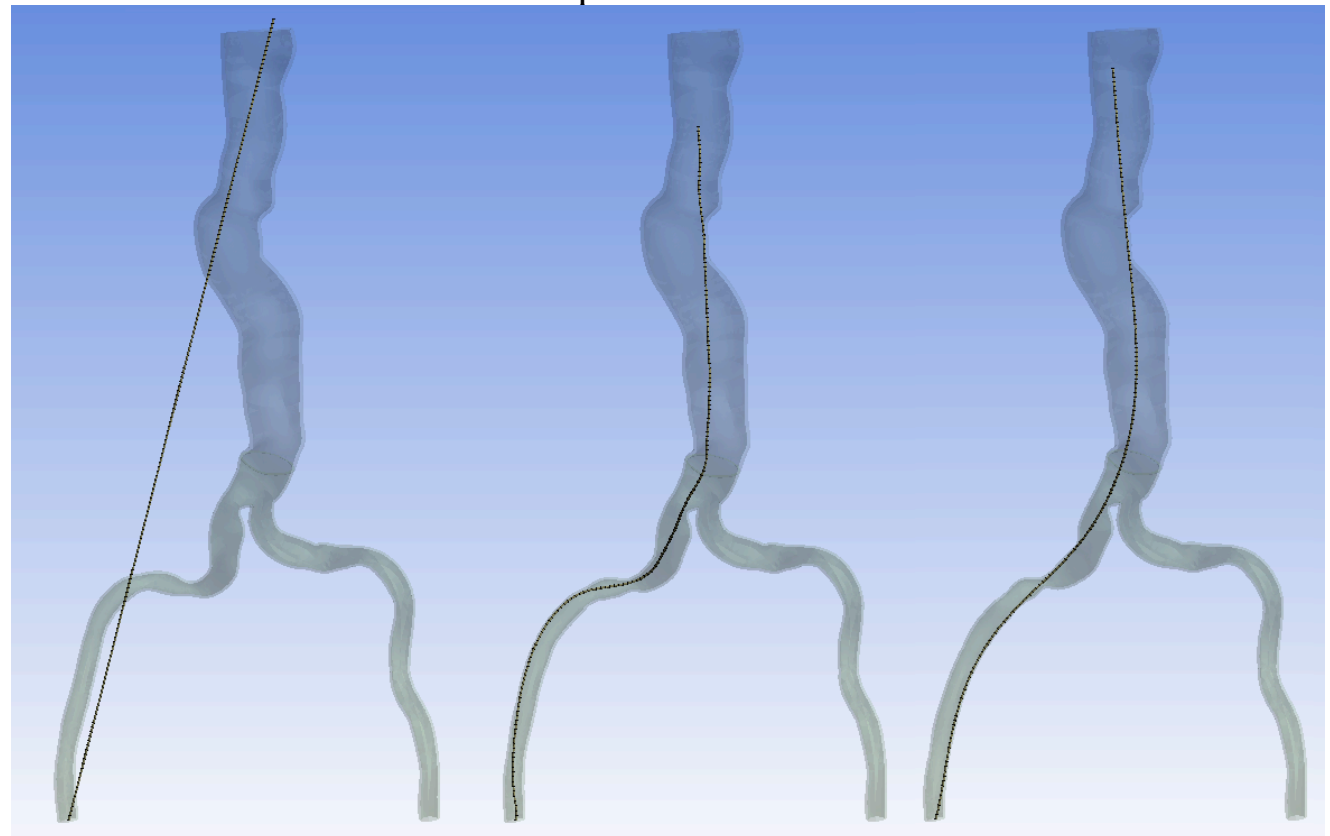

Figure 4: Registration error: mean distance between preoperative 3D centerlines (red) and 2D intraoperative centerlines (blue). Simulation error: mean distance between simulated guidewire (yellow) and real guidewire (black)

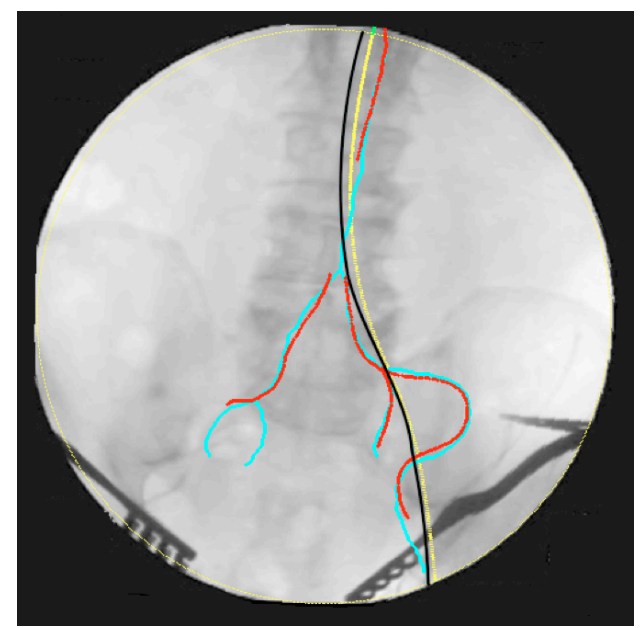


Figure 5: Deformations are quantified from the displacement vector between equivalent points on the undeformed (blue) and deformed (red) centerline and its $\mathrm{x}, \mathrm{y}, \mathrm{z}$ coordinates

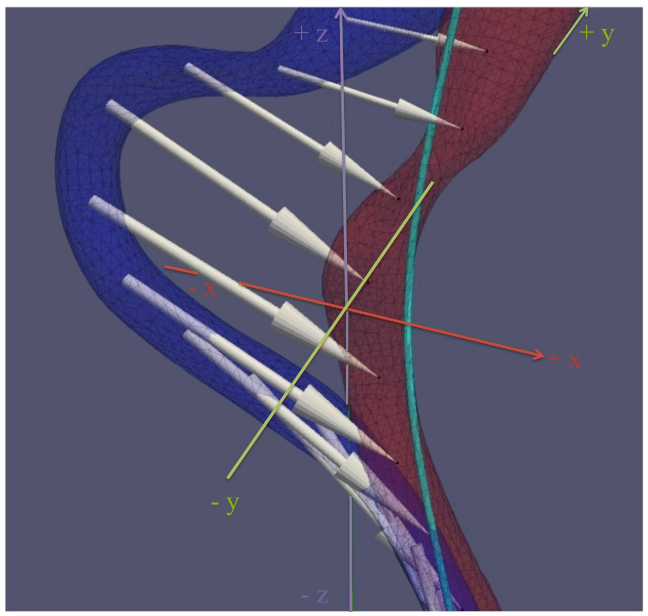

Figure 6. Preoperative volume overlayed (left) onto intraoperative 2D fluoroscopy imaging with the stiff guidewire (in the left iliac artery). On the right, the guidewire is into the left iliac artery of the deformed volume

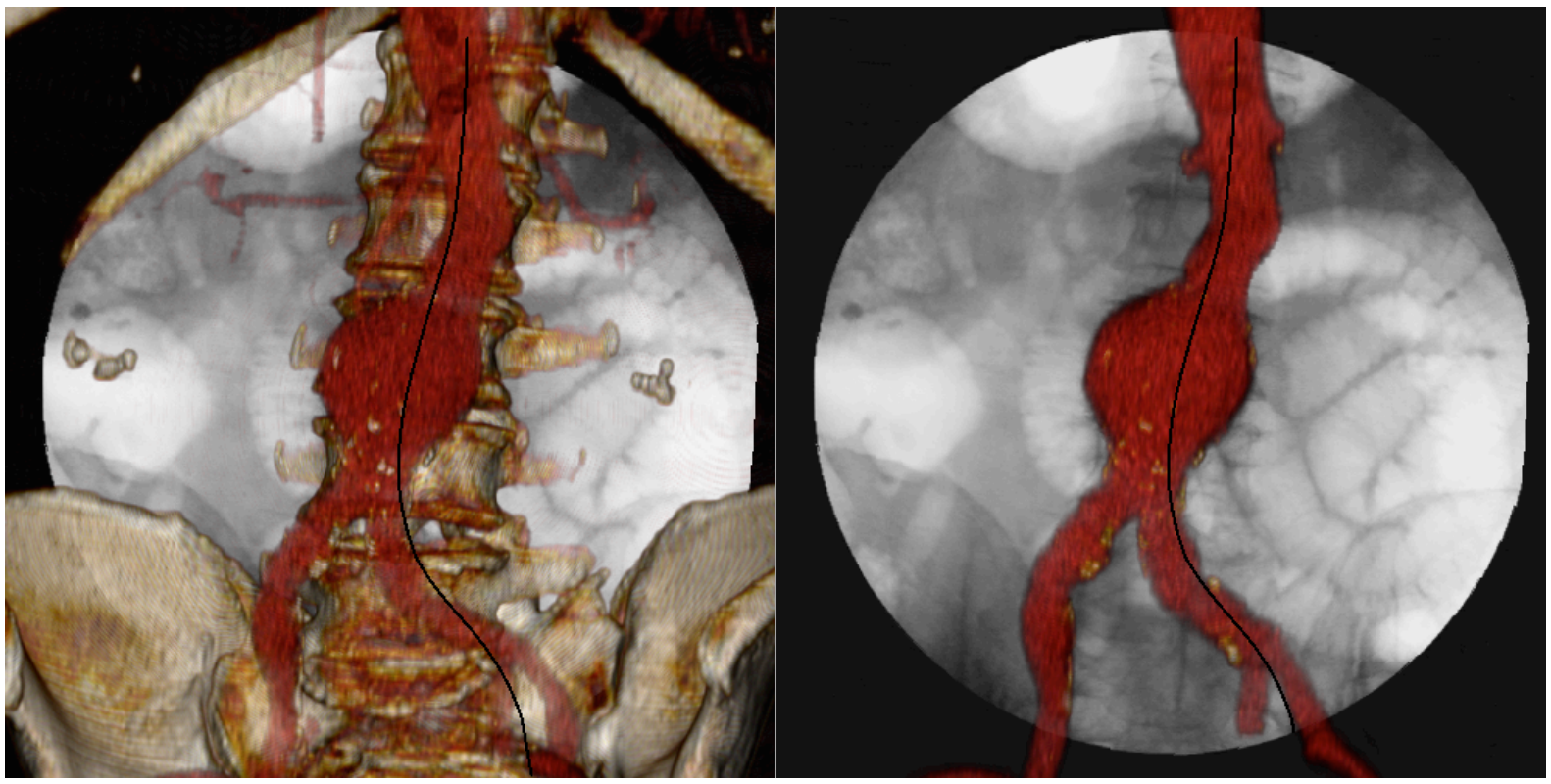


Figure 7. Total length displacement of each point of the centerline along the aorta

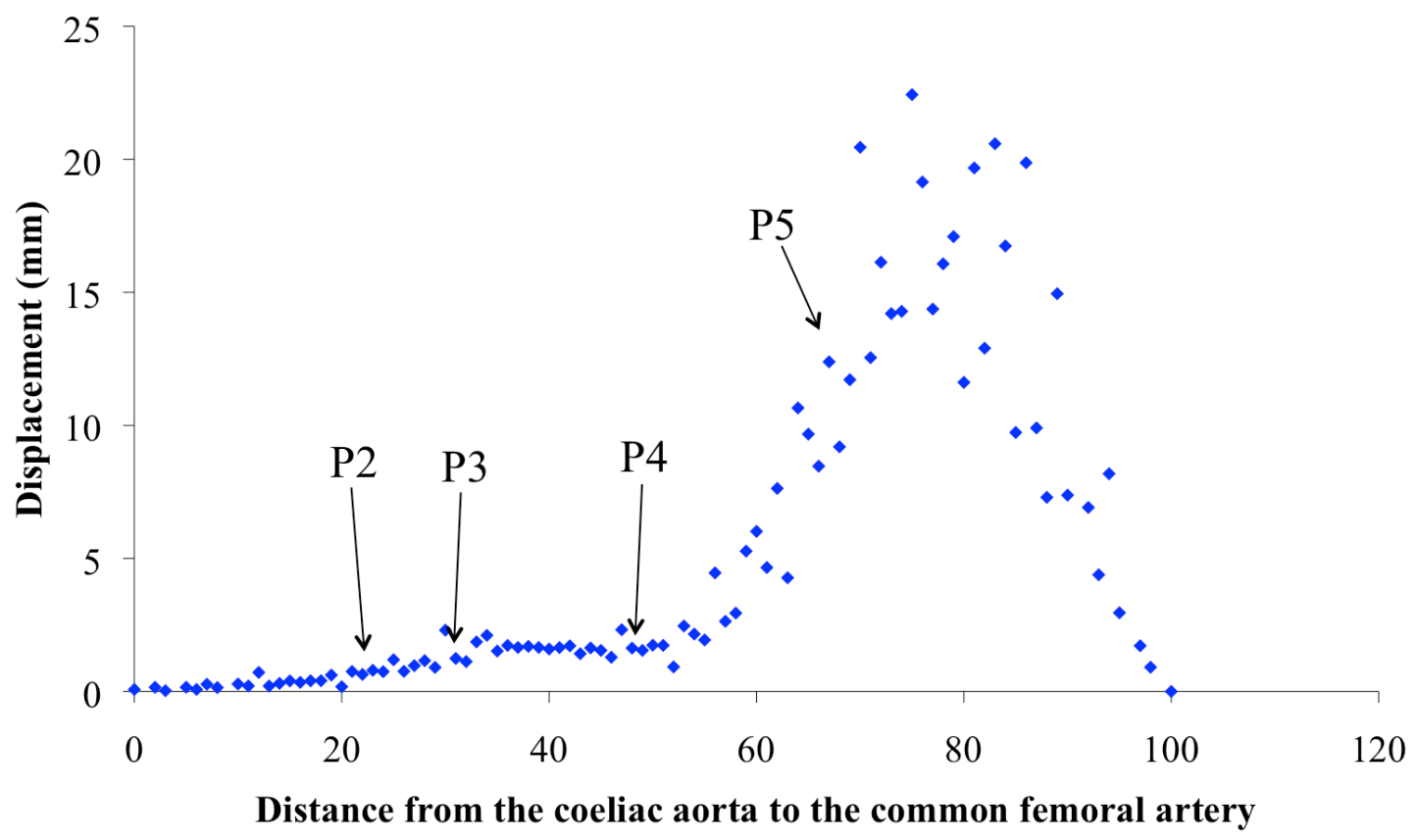

Figure 8. Length displacement of each point of the centerline along the aorta on the x-axis

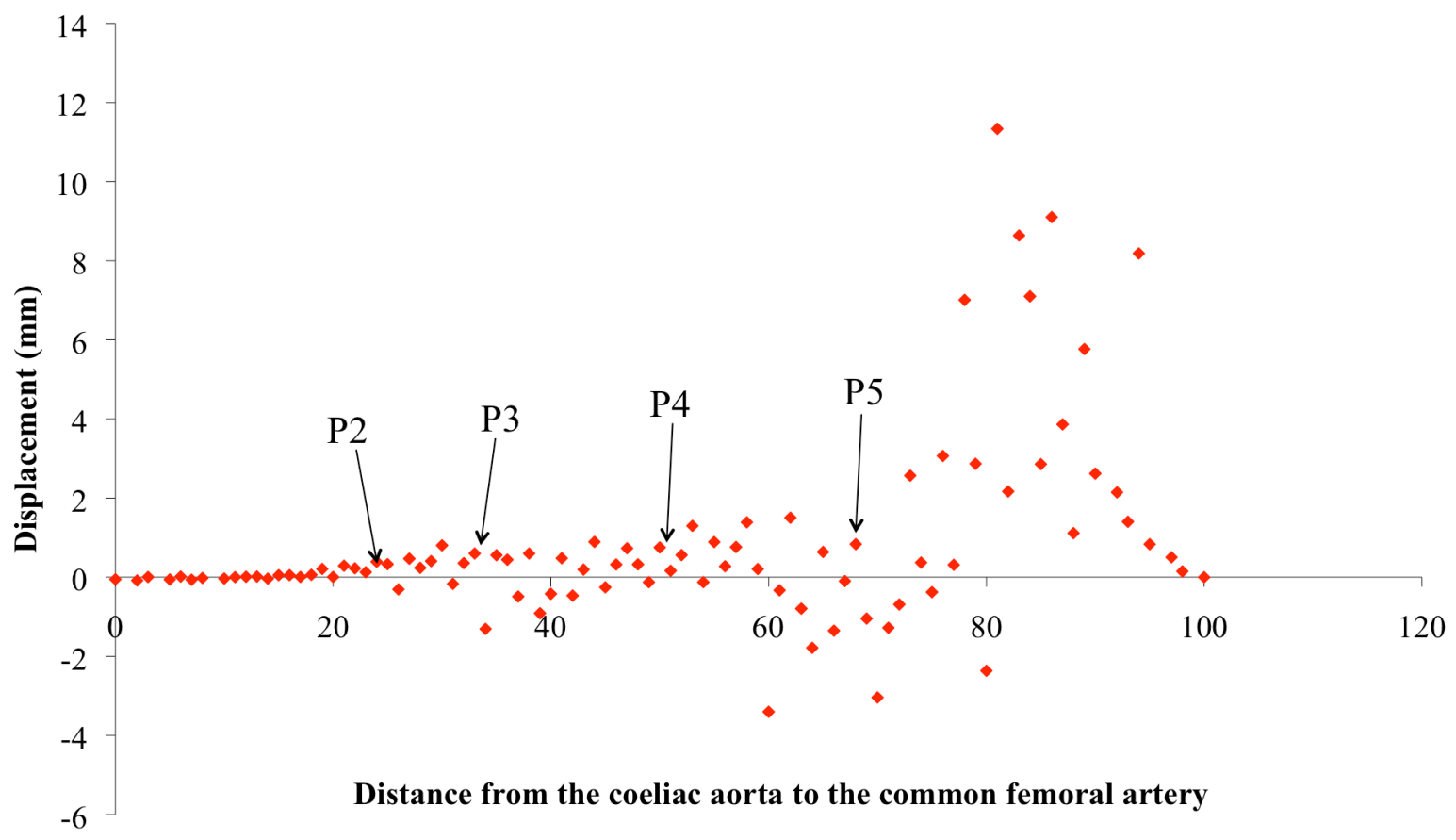


Figure 9: Length displacement of each point of the centerline along the aorta on the y-axis

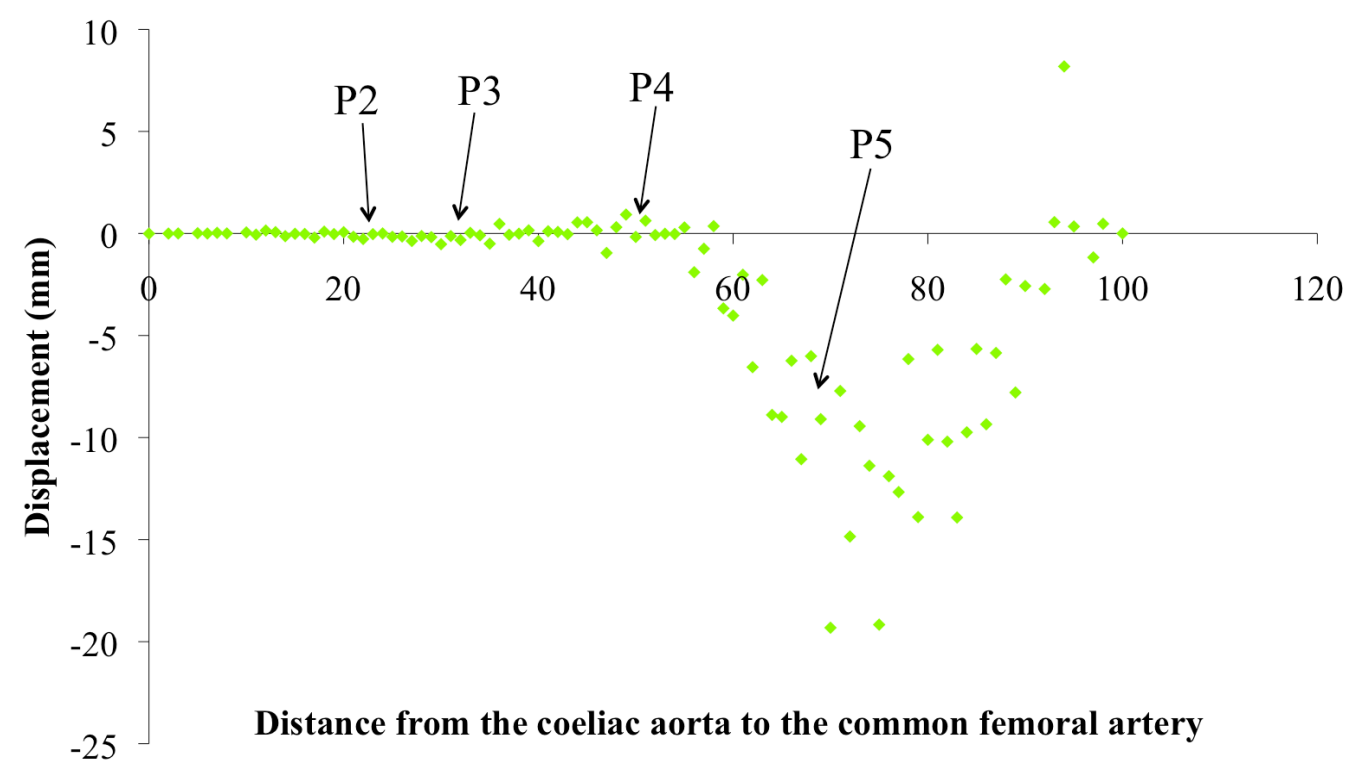

Figure 10: Length displacement of each point of the centerline along the aorta on the z-axis

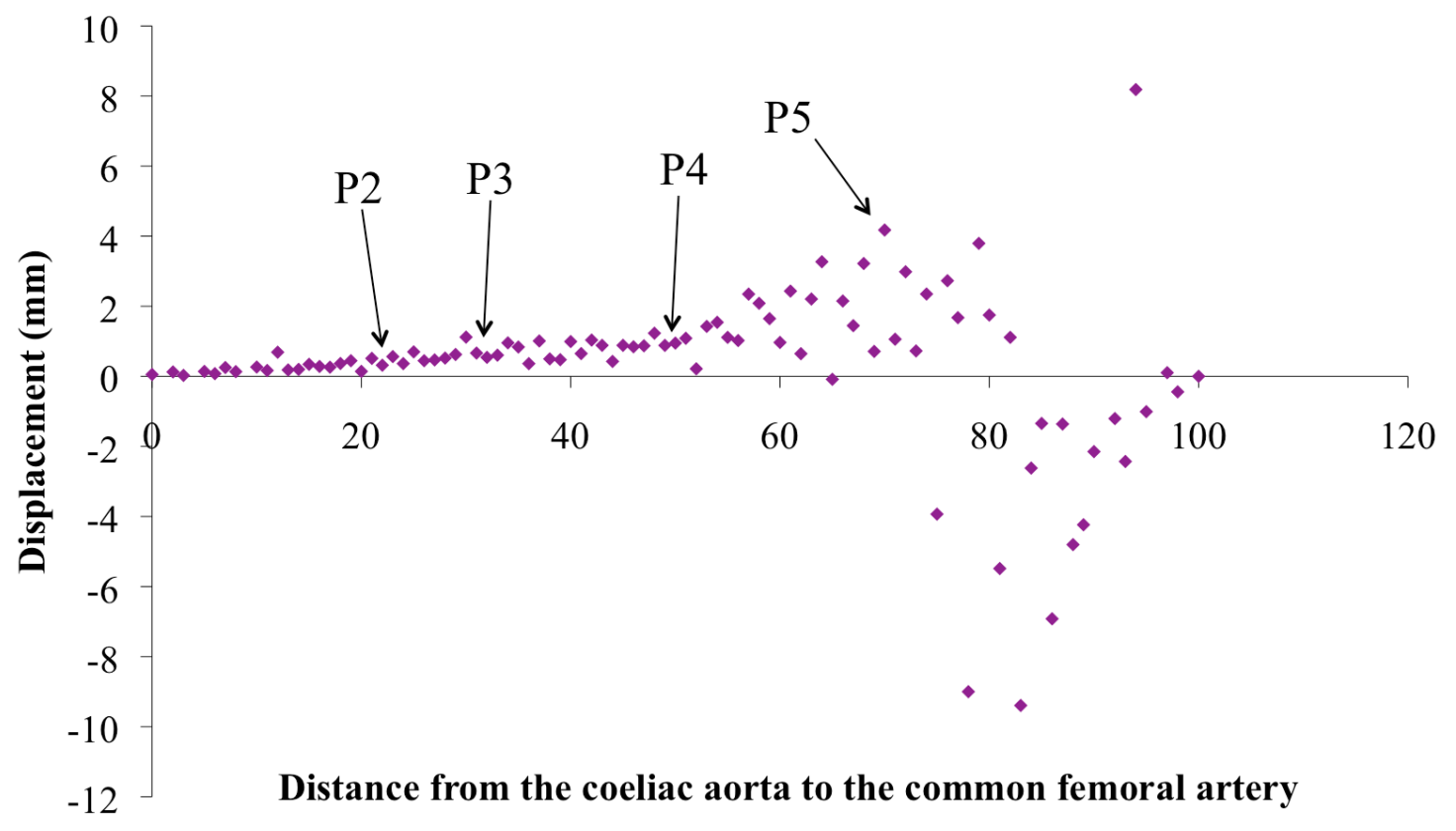

